\title{
Kliniğimizde Tedavi Gören Suriyeli Hastaların Değerlendirilmesi
}

\section{Evaluation of Syrian Patients Treated in Our Clinic}

\author{
Fatma BILLGEN ${ }^{1}$, Alper URAL ${ }^{1}$, Mehmet BEKERECIOOĞLU ${ }^{2}$
}

${ }^{1}$ Dr. Öğr. Üyesi. Kahramanmaraş Sütçü İmam Üniversitesi Tip Fakültesi Plastik, Rekonstrüktif ve Estetik Cerrahi AD, KAHRAMANMARAŞ

${ }^{2}$ Prof. Dr. Kahramanmaraș Sütçü İmam Üniversitesi Tip Fakültesi Plastik, Rekonstrüktif ve Estetik Cerrahi AD, KAHRAMANMARASุ

\section{Öz}

Amaç: Savaş, toplumda fiziksel, sosyal, kültürel ve ekonomik kayıplara neden olan normal hayatı kesintiye uğratan bir felakettir. İnsanlar dünyanın birçok yerinde savaşın olumsuz etkilerine maruz kalmakta ve binlerce sivil kişi hayatını kaybetmekte, ciddi yaralanmalara neden olmakta ve büyük göç dalgalarına bağlı olarak da hastalıkların çeşidi ve dağılımında önemli değişimler gözlenmektedir. Çalışmada, Ocak 2015 ile Mayıs 2018 tarihleri arasında kliniğimize başvuran Suriyeli hastaların, sayısı, demografik özellikleri, görülen hastalık sıklıkları ve uygulanan tedaviler retrospektif olarak incelenmiştir.

Gereç ve Yöntemler: Plastik, Rekonstrüktif ve Estetik Cerrahi Polikliniğinde muayene olmuş, serviste yatarak tedavi görmüş ya da cerrahi müdahale uygulanmış 479 Suriyeli hasta çalışmaya dahil edildi. Görülen hastalıklar, akut yada kronik yara, konjenital anomaliler, skar (kontraktür), maksillofasiyal travma, deri tümörleri ve estetik işlemler olmak üzere 6 grup altında toplanarak incelendi. Toplam hasta sayısının \% 3,4 ünü (479 hasta) Suriyeli hastaların oluşturduğu tespit edilmiştir.

Bulgular: Plastik, Rekonstrüktif ve Estetik Cerrahi savaşlar sırasında ortaya çıan bir cerrahi dal olup, savaşta meydana gelen akut yaralanmaların, yanıkların ve maksillofasial travmaların tedavisi yanı sıra, savaş nedeniyle ya da olumsuz çevre koşullarına bağlı meydana gelen deformite ve anomalilerin tedavisinde de önemli yere sahiptir

Sonuç: Savaşlar veya felaketlere bağlı insan göç hareketleri özellikle komşu ülkeleri en çok etkilemektedir. Bu etkiler sosyo ekonomik olduğu kadar sağlık sorunlarını da içerir. Plastik, Rekonstrüktif ve Estetik Cerrahi her zaman savaşlardan etkilenmiş ve savaş mağduru insanlara yardım etmede öncü rol oynamıştır.

Anahtar Kelimeler: Savaş, göç, sağlık

\section{Abstract}

Objective: War is a disaster that disrupts normal life, which causes physical, social, cultural and economic losses in society. People are exposed to devastating effects of war in many parts of the globe and thousands of civilians are losing their lives. The war causes serious injuries and significant changes in the types and distribution due to large waves of immigration. In this study demographic characteristics, frequency of diseases and treatment types of the Syrian patients whom admitted to our clinic between January 2015 and May 2018 were retrospectively reviewed.

Materials and Methods: Total 479 Syrian patients who had been examined in the Plastic Reconstructive and Aesthetic Surgery outpatient clinic, underwent in-hospital treatment or surgical intervention were included. The diseases were classified into 6 groups as acute or chronic wounds, congenital anomalies, scar (contracture), maxillofacial traumas, skin tumors and aesthetic procedures. $3.4 \%$ of the total number of patients ( 479 patients) were found to be Syrian patients.

Results: Plastic reconstructive and aesthetic surgery is a surgical branch that has emerged and advanced during the wars hence it is essential in the treatment of acute injuries, burns and maxillofacial traumas as well as deformities and anomalies due to war or adverse environmental conditions.

Conclusion: Due to wars or disasters, mass migration of people affects especially neighbouring countries the most. As a result of these facts; health problems as well as economic problems arise. Plastic reconstructive and aesthetic surgery have always played a leading role in helping war victims and people affected by wars

Key Words: War, immigration, health

\section{GİRIŞ}

Savaş, toplumda fiziksel, sosyal, kültürel ve ekonomik kayıplara neden olan normal hayatı kesintiye uğratan bir felakettir. İnsanlar dünyanın birçok yerinde savaşın olumsuz etkilerine maruz kalmakta ve binlerce sivil kişi hayatını kaybetmekte, ciddi yaralanmalara neden olmakta ve büyük göç dalgalarına bağlı olarak da hastalıkların çeşidi ve dağılımında önemli değişimler gözlenmektedir $(1,2)$.

2011 yllında komşu ülke Suriye de başlayan iç savaş nedeniyle Türkiye’ye gelen Suriyeli göçmen sayısı her geçen gün artmakta olup, sayıları 3,5 milyona yaklaşmış durumdadır (3). Sınır bölgesine yakın ilimizde de yaklaşık 100 bin civarı Suriyeli göçmen yaşamaktadır $(3,4)$. Bu veriler göz önüne alındığında savaşta meydana

İletişim: $\begin{aligned} & \text { Dr. Fatma Bilgen, KSÜ Tip Fakültesi Plastik, Rekonstrük- } \\ & \text { tif ve Estetik Cerrahi AD, Kahramanmaraş }\end{aligned}$
DOI:
$\quad \mathbf{1 0 . 1 7 5 1 7 / k s u t f d . 4 5 8 8 1 2}$

gelen akut yaralanmalar yanı sıra, savaşın ve yaşam koşullarının etkilerine bağlı olarak Plastik, Rekonstrüktif ve Estetik Cerrahide karşılaşılan hastalıkların sıklığında önemli değişiklikler gözlenmektedir.

Sunulan çalışmada, önemli sayıda Suriyeli göçmenin yaşadığı ilimizdeki Tıp Fakültesi Hastanesi, Plastik Rekonstrüktif ve Estetik Cerrahi Anabilim Dalına Ocak 2015 ile Mayıs 2018 tarihleri arasında başvuran Suriyeli hastaların, sayısı, demografik özellikleri, görülen hastalık sıklıkları ve uygulanan tedaviler retrospektif olarak incelenmiştir.

\section{GEREÇ VE YÖNTEMLER}

Çalışmamıza, 2018/11/06 no’lu yerel etik kurul

Tel : 05057280165

E-Posta : dfatmabilgen81@gmail.com

Geliş Tarihi : 11.09 .2018

Kabul Tarihi : 08.11 .2018 
onayı alınarak Ocak 2015- Mayıs 2018 yılları arasında Plastik, Rekonstrüktif ve Estetik Cerrahi Polikliniğinde muayene olmuş, serviste yatarak tedavi görmüş ya da cerrahi müdahale uygulanmış 479 Suriyeli hasta dahil edildi.

Hastaların demografik verileri (yaş, cins) ve başvuru nedeni, hastaneye kabulündeki özellikleri, uygulanan tedaviler ve hastanede kalış süreleri gibi klinik bilgileri retrospektif olarak incelendi. Görülen hastalıklar, akut yada kronik yara, konjenital anomaliler, skar (kontraktür), maksillofasiyal travma, deri tümörleri ve estetik işlemler olmak üzere 6 grup altında toplanarak incelendi.

Elde edilen tüm veriler SPSS 17.0 istatistik paket programinda analiz edildi.

\section{BULGULAR}

Çalışmaya dahil edilen toplam 479 olgunun 207'si kadın (\% 43.2), 272'si erkek (\% 46.8) idi. Ayrıca Ocak 2015-Mayis 2018 tarihleri arasında kliniğimize müracaat eden toplam hasta say1s1 13947'dir. $\mathrm{Bu}$ hastane otomasyon sisteminden yillık hasta sayıları belirlenip toplanarak bulunmuştur ve toplam hasta sayisinin \% 3,4 'ünü (479 hasta) Suriyeli hastaların oluşturduğu tespit edilmiştir.

Yillara göre hasta dağılımına baktığımızda 197 hasta ile en fazla 2017 yllında başvuru olduğu gözlendi. Hastalık gruplarına göre hasta sayılarına baktığımızda
Grafik 3: Hastalık dağılımının görüntüsü

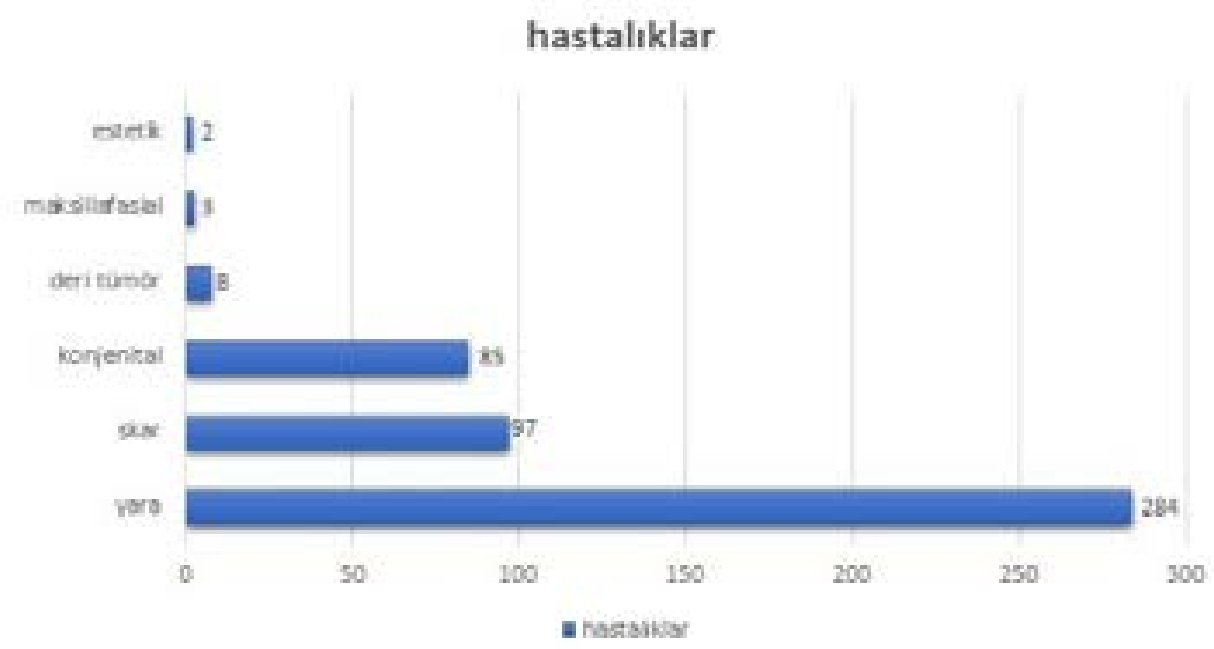

Grafik 1, 2: Yara ve skar hastalarının vücut bölgelerine göre dağılımı
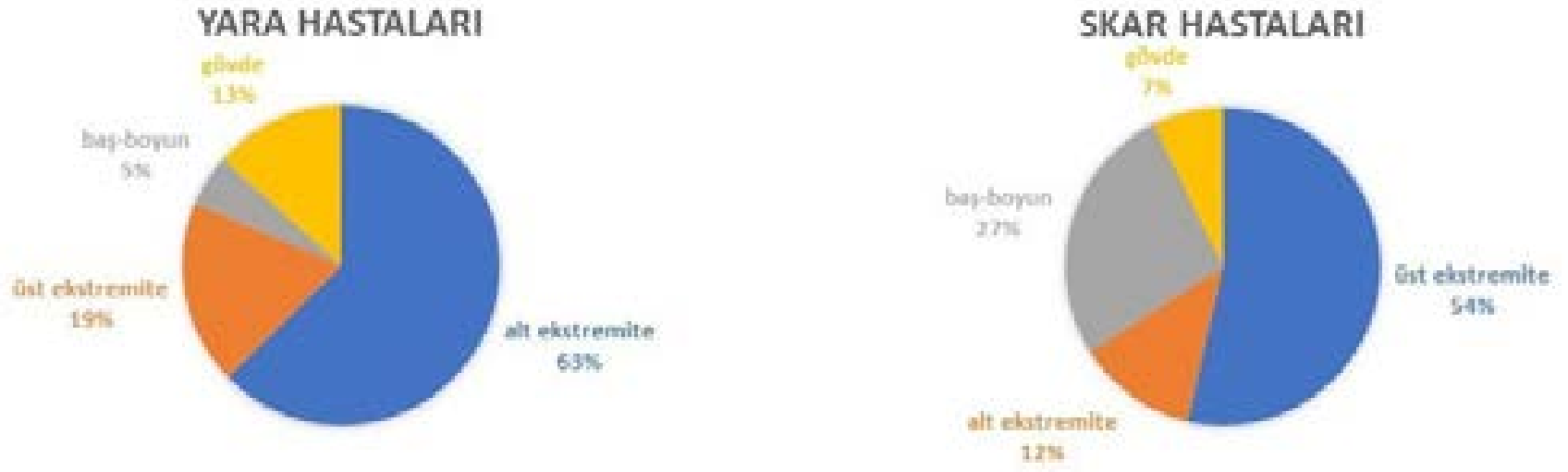

yarası olan hastaların sayısının 284 (\% 59.29) olduğu ve yaralamalarında $178^{\prime}$ inin (\% 62,6) alt ekstremitede,

Yıllara ve hastalık grubuna göre hasta dağılımları Tablo 1.de gösterilmiștir.

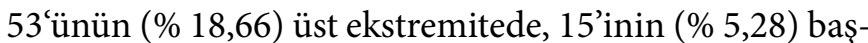
boyun bölgesinde ve 38 'inin (\% 13,38) gövdede olduğu tespit edildi.

Skar hastalarının sayısının da 97 (\% 20.25) olduğu ve tüm skarların 52 (\% 53,6) hasta ile en sık üst ekstremitede, 12 (\% 12,37) hastada alt ekstemitede, 26 ( \% 26,80) hastada bas boyun bölgesinde ve 7 (\% 7,21) hastada gövde yerleşimli olduğu gözlendi (Grafik 1, 2).

Konjenital anomalili hasta sayısının 85 (\% 17.74) olduğu, en sık konjenital anomalinin de 69 (\% 81,17) hasta ile yarık damak dudak olduğu, ardından $13(\%$ $15,29)$ hasta ile el anomalilerinin ve $3(\% 3,52)$ hasta ile de hipospadias olduğu gözlendi. Maksillafasiayal travmalı hasta sayısı 3 (\% 0.62) olup hepsinin multiple fraktürleri ( maksilla, mandibula, zigoma) olduğu görüldü. Deri tümör olgularının sayısı 8 (\% 1.67) olup, tüm tümör hastalarının 5’i (\% 62,5) bazal hücreli karsinom, 3’ü (\% 37,5) skuamöz hücreli karsinomdu. Estetik hastalarının sayıs1 2 (\% 0.41) olup, biri mammoplasti, diğerinin abdominoplasti ameliyatı olduğu görüldü (Grafik 3 ). 
Tablo 1. Hastalık ve yıllara göre hasta dağılımı (E: Erkek, K: Kadın)

\begin{tabular}{|l|l|l|l|l|l|}
\hline & \multicolumn{1}{|c|}{2015} & \multicolumn{1}{|c|}{2016} & \multicolumn{1}{|c|}{2017} & \multicolumn{1}{|c|}{2018} & \multicolumn{1}{|c|}{ Toplam } \\
\hline $\begin{array}{l}\text { Konjenital } \\
\text { anomali }\end{array}$ & $9(4 \mathrm{E}, 5 \mathrm{~K})$ & $16(11 \mathrm{E}, 5 \mathrm{~K})$ & $40(21 \mathrm{E}, 19 \mathrm{~K})$ & $20(11 \mathrm{E}, 9 \mathrm{~K})$ & $85(47 \mathrm{E}, 38 \mathrm{~K})$ \\
\hline Skar & $7(2 \mathrm{E}, 5 \mathrm{~K})$ & $38(17 \mathrm{E}, 21 \mathrm{~K})$ & $37(17 \mathrm{E}, 20 \mathrm{~K})$ & $15(3 \mathrm{E}, 12 \mathrm{~K})$ & $97(39 \mathrm{E}, 58 \mathrm{~K})$ \\
\hline Yara & $31(11 \mathrm{E}$, & $94(43 \mathrm{E}, 51 \mathrm{~K})$ & $114(58 \mathrm{E}, 56 \mathrm{~K})$ & $45(24 \mathrm{E}, 21 \mathrm{~K})$ & $284(136 \mathrm{E}, 148 \mathrm{~K})$ \\
\hline $\begin{array}{l}\text { Deri Tümör- } \\
\text { leri }\end{array}$ & $1(1 \mathrm{~K})$ & $4(3 \mathrm{E}, 1 \mathrm{~K})$ & $3(1 \mathrm{E}, 2 \mathrm{~K})$ & & $8(4 \mathrm{E}, 4 \mathrm{~K})$ \\
\hline $\begin{array}{l}\text { Maksillofasial } \\
\text { Travma }\end{array}$ & & & $1(1 \mathrm{E})$ & $2(2 \mathrm{E})$ & $3(3 \mathrm{E})$ \\
\hline $\begin{array}{l}\text { Estetik } \\
\text { Toplam hasta } \\
\text { sayıs }\end{array}$ & $\begin{array}{l}48(18 \mathrm{E}, 30 \\
\mathrm{K})\end{array}$ & $152(74 \mathrm{E}, 78 \mathrm{~K})$ & $197(98 \mathrm{E}, 99 \mathrm{~K})$ & $82(40 \mathrm{E}, 42 \mathrm{~K})$ & $479(229 \mathrm{E}, 250 \mathrm{~K})$ \\
\hline
\end{tabular}

Hastalık grupları değerlendirildiğinde, en fazla hastanın yarası olan hasta grubunda olduğu ve bunun da savaşta meydana gelen ateşli silah yaralanmaları ya da patlamalar sonucu oluştuğu belirlendi. İkinci sırada gözlenen skar hastalarının savaş sırasında oluşan yanıklar ya da yaşam koşulların bağlı olarak çadırlarda çıkan yangınlarda meydana gelen yanıklar sonucu oluştuğu tespit edildi. Konjenital anomalili hastalara baktığımıza da en fazla yarık damak dudak hastalarının olduğu ve yıllar içinde sayısının giderek arttığı görülmektedir. $\mathrm{Bu}$ durumun savaşın çevresel etkilerine ve yaşam koşullarına bağlı olduğu düşünülmektedir.

\section{Hastaların yaşları 0 ile 91 arasında} değişmekte olup, ortalama yaş 18,3 $\pm 2,8$ olarak tespit edildi (Tablo 2). Hastalar yaşlarına göre 0-20 yaş, 2040 yaş, 40-60 yaş ve 60 yaş üstü diye gruplara ayrılarak incelendiğinde, $0-20$ yaş arası $309(\% 64,5), 20-40$ yaş arası 117 (\% 24,47), 40-60 yaş arası 31 (\% 6,47), 60 yaş üstü 22 (\% 4,59) hasta olduğu tespit edildi. Bu dağılıma göre savaşın olumsuz etkilerine en fazla çocuk ve gençlerin maruz kaldığı söylenebilir.

Hastalık gruplarına göre yaş dağılımına bakıldığında, yarası olan hastaların yaş ortalamasının $24.17 \pm 2,75$, konjenital anomalili hastaların yaş ortalamasının 4.21 2 2,34, skar hastalarının yaş ortalamasının $10.23 \pm 3,15$ olduğu görüldü. Sonuçlara bakıldığında, savaşta en fazla genç nüfusun ve çocukların etkilendiği görülmektedir. Genç nüfusta savaşta meydana yaralanmalar fazla görülürken, çocuklarda yanıklara bağlı skarlar fazla görülmektedir. Ayrıca savaş sonrası meydana gelen doğumlarda da yarık damak dudak başta olmak üzere konjenital anomali oranının arttığı görülmektedir.

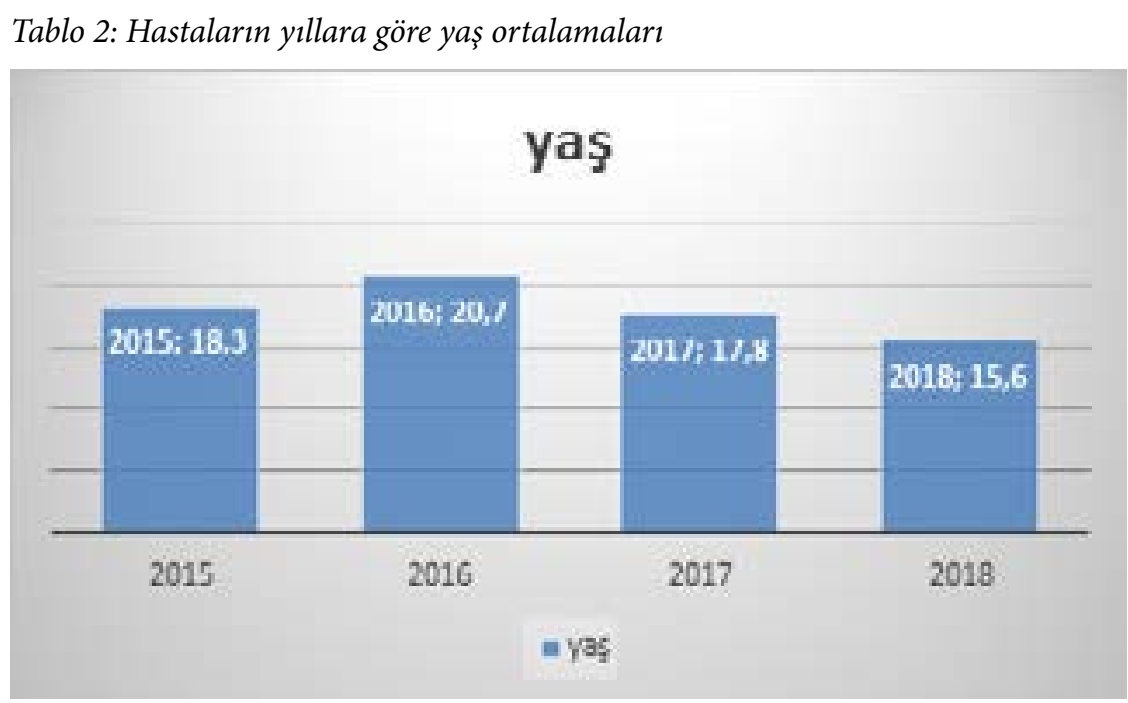

\section{TARTIŞMA}

Mülteci sorunu, yoksulluk, afet, savaş gibi durumların tüm dünyada varlığını devam ettirmesiyle gittikçe artan bir öneme sahip olmaktadır. Son yıllardaki en büyük mülteci sorunu Suriye'deki iç savaş nedeniyle Türkiye başta olmak üzere farklı komşu ülkelere büyük göç dalgaları nedeniyle ortaya çıkmaktadır. 2018 yılı itibariyle ülkemizde yaşayan Suriyeli sı̆̆ınmacı sayısının 3,5 milyona yaklaştığı ve sınır bölgesine yakın ilimizde de Suriyeli göçmen sayısının 100 bin civarında olduğu bilinmektedir. Ülkemizdeki tüm Suriyeli göçmenlerin \% 2,8'ini oluşturmaktadır (3-5).

Plastik, Rekonstrüktif ve Estetik Cerrahi savaşlar sırasında ortaya çıkan bir cerrahi branş olup, savaşta meydana gelen akut yaralanmaların, yanıkların ve maksillafasial travmaların tedavisi yanısıra, savaş nedeniyle ya da olumsuz çevre koşullarına bağlı meydana gelen deformite ve anomalilerin tedavisinde de önemli yere sahiptir $(6,7)$.

$\mathrm{Bu}$ veriler göz önüne alındığında, Suriye’deki 
iç savaşın Plastik, Rekonstrüktif ve Estetik Cerrahi de oluşturduğu etkiler, hastaların demografik özellikleri, sayıları ve hastalık çeşitleri ile ilgili yapılmış çalışma bulunmamaktadır.

Çalışmaya dahil edilen 479 hastanın 284 'ü yarası olan hasta olup, savaşta meydana gelen yaralanmalara bağlı olarak oluşmuștu. Yara hastalarının yaş ortalaması 24,17 olarak tespit edildi. Tüm hastaların \% 59,2'si yara hastası idi. Bu durum da genç erişkinlerin savaş nedeniyle ülkelerinde kaldığını, ateşli silah, bomba ve patlamalara maruz kalarak yaralandıklarını düşündürmektedir.

Savaş ve benzeri felaketlerin ülkeleri ve etrafındaki komşu ülkeleri etkilemesi kaçınılmaz bir durumdur. Felaketlere bağlı sosyo-ekonomik durumun kötüleşmesi ile o bölgelerde yaşayan insanların durumunda farklılıklar ve kötüleșmeler olmaktadır. Kötü beslenme ve hijyen bozukluğu birçok konjenital anomali etyolojisinde rol almaktadır $(8,9)$. Bizim kliniğimize başvuran yarık damak dudaklı hastaların etiyolojisinde bu faktör etkili olabilir.

Savaşa bağlı yaralanmalar ve yaraya bağlı uzun süren tedaviler belli bir masrafı da yanında getirmektedir. Ayrıca yaralanmalar sonrası oluşan skarların tedavisi bazen yillar sürmekte ve birden fazla ameliyat gerektirmektedir (10). Hatta bu tip hastalara kullanılan ortez, protez veya tedaviye yardımcı tıbbi cihazlar da ayrıca ekonomik harcamalara yol açmaktadır $(10,11)$.

Sonuç olarak savaşlar veya felaketlere bağlı insan göç hareketleri özellikle komşu ülkeleri en çok etkilemektedir. Bu etkiler sosyo- ekonomik olduğu kadar sağlık sorunlarını da içerir. Plastik Rekonstrüktif ve Estetik Cerrahi her zaman savaşlardan etkilenmiş ve savaş mağduru insanlara yardım etmede öncü rol oynamıştır.

\section{KAYNAKLAR}

1. İnci R, Öztürk P, Mülayim MK, Karakuzu A, Kelekçi KH, İnci MF. Suriye savaşının dermatolojik yüzü. Arch Turk Dermatol Venerology 2016; 50: 145-9.

2. Yurtseven A, Özcan G, Saz EU. Çocuk Acil Servise Başvuran Suriyeli Hastalarla Türk Hastaların Karş1laştırılması: Ege Üniversitesi Deneyimi. CAYD 2015; 2: 133-6.

3. Syria Regional Refugee Response. Turkey,Inter-agency Information Sharing Portal, 2018. Accessed at August 29, 2018 at http:// data.unhcr.org/syrianrefugees/country.php

4. Akkucuk S, Aydogan A, Yetim I, Ugur M, Oruc C, Kilic E, et al. Surgical outcomes of a civil war in a neighbouring country. J R Army Med Corps 2016; 162: 256- 60.

5. Yuce Y, Acar HA, Erkal KH, Arditi NB. Retrospective analysis of patients with burn injury treated in a burn center in Turkey during the Syrian civil war. Saudi Med J 2017; 38: 93-96.

6. Wallace AB. The history and evolution of plastic surgery. Res Medica. 1965;4 : 7-10.

7. Temi YB, Sedef AM, Gokcay S, Coskun H, Kaplan SO, Ozkul O, et al. A study on basic demographic and disease characteristics of cancer-diagnosed Syrian refugees treated in the border city of Turkey, Sanliurfa; a hospital-based retrospective case series study. JBUON 2017; 22: 1591-1594.

8. Gunduz M, Sekmenli T, Ciftci İ. Reflection of Syrian Refugees to Pediatric Surgery. Int J Cur Res Rev 2018; 10: 21-24.

9. Çıldır ŞK, Çalışkan S, Sandallı N. Dudak-Damak Yarıklarında Etiyoloji, Embriyoloji, Klinik Bulgular ve Tedavi. Ondokuz Mayıs Üniversitesi Diş Hekimliği Fakültesi Dergisi 2010; 11:103-108.

10. Tahirbegolli B, Çavdar S, Sümer EÇ, Akdeniz SI, Vehid S. Outpatient admissions and hospital costs of Syrian refugees in a Turkish university hospital. Saudi Med J 2016; 37: 809-812.

11. Duramaz A, Bilgili MG, Bayram B, Ziroğlu N, Bayrak A, Avkan MC. Orthopedic trauma surgery and hospital cost analysis in refugees; the effect of the Syrian civil War. International Orthopaedics (SICOT) 2017 41: 877-884. 